\title{
List of oral and Poster publications
}

\section{OP 001}

Using intellectual property system as an incentive for innovation in healthcare sector: A Sri Lankan perspective

Punchihewa NS, Weerakoan TP

\section{OP 002}

Non-invasive assessment of vasodilatory endothelial dysfunction during reactive hyperemia

Samarawickrama KG, Perera ND, De Silva AC, Jayasinghe S

OP 003

Development of systems to profile foot plantar pressure and temperature of diabetic feet

Warnakulasuriya AS, Ariyarathna HPAR, Dias AAC, Dinushka NY, Ramraj C, De Silva AC, Jayasinghe S

OP 004

$\overline{\text { Population pharmacokinetics model development }}$ and validation using pharmacokinetics data of amoxicillin to predict amoxicillin concentrations for a Sri Lankan population

Thambavita D, Galappatthy P, Jayakody RL

\section{OP 005}

Climatic factors influencing dengue transmission in Southern and Eastern Provinces, Sri Lanka

Bandara AGGC, Priadarshana PHMGC

OP 006

An assessment of authenticity in Sri Lankan undergraduates

De Zoysa P, Kumar S, Amarasuriya SD, Mendis NSR

OP 007

Envy among students of a university in Sri Lanka

De Zoysa P, Kumar S, Amarasuriya SD

OP 008

Breaking the fear wall: Building confidence to speak English - A psychological approach to teach English Attanayake AU

\section{OP 009}

Bioaccumulation of toxic trace elements in autopsied human kidney tissues from Sri Lanka: A preliminary assessment of potential exposure through drinking water

Gunawardana JW, Chandrajith R, Thoradeniya T, Jayasinghe S, Gunawardena SA
OP 010

Liver diseases among Sri Lankan adults: An autopsy study from Colombo

Katulanda P, Gunatilake S, Dissanayake HA, Somasundaram NP, Katulanda GW, Anthonis S, Galappaththy SL, de Silva AHN, Serasinghe KTMPH, Anupama NHJP, Hettiarachchi HACL, Ranaweera GG, Wijesinghe HD, Priyani AAH, de Silva MVC, Tennakoon A

OP 011

Development of Medical Humanities in Sri Lanka: A pioneering initiative by the Faculty of Medicine, University of Colombo

Amarasuriya SD, Jayasinghe S

OP 012

Prevalence of nomophobia and its effect on psychological well-being in smartphone using undergraduates of a selected medical faculty in Sri Lanka

Meegoda VJ, Mapa MMYNB, Matharage AS, Gunathilake N

OP 013

Influence of music tempo on heart rate, blood pressure and respiratory rate changes in treadmill walking exercise of untrained undergraduate students

Kumaradasa PP, Siridewa K, Ranasinghe DC

OP 014

How prepared the undergraduate medical students for blended learning: Assessing Learning Management System readiness and Information and Communication Technology use

Samarasinghe DAN, Hewapathirana R, Dissanayake VHW

OP 015

Implementation of an artificial intelligence algorithm to predict clinical phenotypes from genome data

Perera PSD, Hewapathirana R, Dissanayake VHW

OP 016

Radioiodine thyroid remnant ablation - 10-year experience

Premasiri DGKMM, Nanayakkara DKK, Nawaz SI, Gawarammana MMJK

DOI: http://doi.org/10.4038/cjms.v56i2.4975

This is an open-access article distributed under the terms of the Creative Commons Attribution 4.0 International License, which permits unrestricted use, distribution, and reproduction in any medium, provided the original author and source are credited. 
OP 017

Urinary leukotriene $\mathrm{E}_{4}$ levels as a biomarker of disease severity in patients with acute dengue infection

Silva YSHTD, Gomes L, Mahapatuna SD, Wickramatunga CK, Jeewandara C, Wijewickrama A, Ogg G, Malavige GN

OP 018

The association between human papillomaviral infections and esophageal cancers in a group of Sri Lankan patients

Chandani GGY, Wathupola A, Fernandopulle S, Perera KA, Udagama PV

\section{OP 019}

A model to integrate diabetic and the eye clinics to deliver care for diabetic retinopathy via teleophthalmology

De Silva ANM, Gurusamy V, Marasinghe RB

OP 020

Effectiveness of trigger point dry needling for specific and non-specific chronic lower back pain Muthurajan, Greene

OP 021

Risk factors for pulmonary tuberculosis in males and females

Hemachandra CD, Pathmeswaran A, Samaraweera S

OP 022

Validation of the WHO/ISH risk prediction chart for South East Asian Region B (SEAR B) countries in Sri Lanka

Thulani UB, Warnakulasuriya DTD, Peiris TSG, Kasturiratne KTAA, Ranawaka UK, Chakrewarthy S, Kurukulasooriya SAF, Mettananda KCD, Niriella MA, De Silva ST, Pathmeswaran AP, De Silva HJ, Wickremasinghe AR

OP 023

Prevalence of abnormal ovarian masses in women over 40 years of age in the District of Colombo, Sri Lanka

Gunathilake KAMP, Kumarapeli V, Kaluarachchi A, Hunukumbure RMCB

OP 024

Gallbladder oedema and pericholecystic fluid in dengue fever, as a marker of progression, plasma leakage and severe dengue

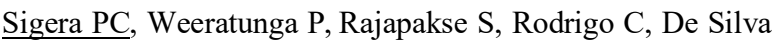
NL, Jayasinghe S, Handunnetti S, Fernando SD
OP 025

Post-market bioequivalence studies for two medicinal products available in Sri Lanka

Mannapperuma U, Thambavita D, Galappatthy P, Jayakody RL

OP 026

Leishmaniasis in Sri Lanka revisited: Analyses reveal novel epidemiological findings

Deepachandi MAB, Siridewa K, Dayananda MAS, Gange YR, Weerasinghe CS, Akarawita J, Gunasekara C, Wickremarathne C, Warnasuriya W, Ranawaka RR, Udagedara C, Sirimanna G, Chandrawansa PH, Ariyawansa D, Kahawita I, Karunaweera N D, Siriwardana HVYD

\section{OP 027}

Serum leptin levels among adolescents in Colombo district, Sri Lanka: relationship with sex, adiposity and pubertal development

Abeyratne RMTB, Perera PPR, Fernando DMS

\section{OP 028}

Grounded theory on therapy compliance of

Mindfulness Based Cognitive Therapy: An exploratory reviewing

Aththidiye SR, Wanigaratne S, Dissanayake MP, Kathriarachchi S

\section{OP 029}

Weight-based thiopurine dosing in inflammatory bowel disease does not correlate with achievement of therapeutic drug levels

Mitrev N, Ward M, Blaker P, Irving P, Sanderson J, Kariyawasam V

OP 030

Early thiopurine maintenance is associated with reduced colectomy rate and proximal disease progression in ulcerative colitis

Mitrev N, Mourad FH, Paramsothy S, Selinger CP, Katelaris PH, Jones B, McDonald C, Barr G, Chapman G, Cowlishaw J, Andrews J, Leong RW, Kariyawasam VC

OP 031

Association of plasmablasts and dengue specific antibody responses with clinical disease severity in dengue infection

Wijesinghe AM, Gamage GDJ, Goonewardana H, Gomes L, Jayathilaka D, Wijeratne DT, De Alwis R, Jeewandara C, Wijewickrama A, Ogg GS, Malavige GN

OP 032

Shedding light on challenges of children with $46, \mathrm{XY}$ Disorders/Differences in Sex Development

Seneviratne SN, Wickramaarachchi WAYA, Jayawardene GDCH, de Silva KSH 
OP 033

Non-invasive technology development to identify the endothelial dysfunction

Kodithuwakku KP, Munasingha SC, Vithanage CW, Jayasinghe S, Constantine GR, Senarath U

OP 034

Anatomic correction of transposition of the great arteries in neonates and infants in Sri Lanka

Singappuli K

OP 035

Associations of baseline hip shape with knee osteoarthritis outcomes over 12 years in older adults: An exploratory analysis in a populationbased cohort

Munugoda IP, Ahedi HG, Aspden RM, Mattap SM, Wills K, Graves SE, Lorimer M, Cicuttini F, Gregory JS, Jones G, Callisaya ML' Aitken DA

OP 036

Efficacy and safety of a novel therapy with Sodium Glucose Co-Transporter Inhibitor (SGLT2) empagliflozin in the treatment of type 2 diabetes in Sri Lanka

Katulanda P, Dilrukshi MDSA, Vithiya R, Dissanayake HA, de Silva PHLU, Bandara P

OP 037

Fasting plasma glucose, oral glucose tolerance test and $\mathrm{HbA1c}$ in diagnosing diabetes and prediabetes: An analysis from a high-risk South Asian population Katulanda P, Chambers JC, Katulanda GW, Dissanayake HA, Jayawardana R, Gamage MKW, Anthonis SP, Weerasinghe APM, De Silva PHLU

OP 038

Profile of paediatric solid tumours in Sri Lanka: A retrospective analysis

Wijayawardhana KWSM, Meegoda VJ, Mahathanthila WDTA, Kumarasinghe N, Munasinghe TD, Bright BP, Wijekoon N, Gunaratne SA, Perera U

OP 039

Melioidosis: Unearthing a subterranean infection in Sri Lanka

Corea EM, Masakorala J, Seneviratne P

OP 040

Role of virtual medicine visits in medical care delivery in Sri Lanka

Manoharan S
OP 041

Validation of a computer programme for diagnosis in primary care: Computer Assisted Medical Evaluation of Symptoms (CAMEOS-P)

$\underline{\text { Perera A }}$

OP 042

Real-time physiological data stream analytics for ICU clinical decision support

Wijesurendra M, Ranasinghe DN

OP 043

Validation of a Diet Prescription Generator (DPG): A Computerized Decision Support System (CDSS) for physicians

$\underline{\text { Perera A }}$

OP 044

Initial reaching behaviours of Sri Lankan Facebook users towards a peer profile with manifestations of depression: An online descriptive study

Ruwanpathirana P, Amanda H, Chulasiri P, Rajasuriya M

OP 045

Approach of Facebook users towards possible suicide risk of a peer with online manifestations of depression: A descriptive study among Sri Lankan Facebook users

Amanda H, Ruwanpathirana P, Chulasiri P, Rajasuriya M

OP 046

Blooming of Faculty of Medical Sciences at University of Sri Jayewardenepura; Nurturing role of Colombo Medical Faculty

Yasawardene SG

OP 047

The pattern of social media use and its impact on studying and social spheres in science stream advanced level students of three districts in Sri Lanka

Madhushan THS, Mandanayake MAIC, Mathumai T, Dayabandara M

OP 048

Suffer yet alive: sociological perspectives of diabetes Abeywardhana DMY, Ranasinghe PKGIL, Kunaratnam L

OP 049

Health nutrition and lifestyle intervention for cardiovascular disease risk reduction in a middle aged Sri Lankan population: baseline assessment of a randomized controlled trial

Senarath U, Katulanda P, Fernando DN, Kalupahana NS, Partheepan K, Dibley MJ 
OP 050

A home visits program to promote issues related to home-based care

Samarasekara K, Madurapperuma C, Gomez D, Jayasinghe S

OP 051

Traffic induced ultra-fine particle exposure of park users: case of roadside parks in the city of Colombo, Sri Lanka

Rajapaksha I, Ekanayake M, Jayasinghe S

OP 052

Effectiveness of an aerobic exercise programme on cardiovascular endurance and body weight in sedentary overweight female undergraduates of the University of Colombo and their knowledge, attitudes, concerns and expectations regarding aerobic exercises

Premarathna MMLD, Weeraratne CL

OP 053

Obesity, energy balance and planetary health: Estimated impacts from a low-middle income country

Dissanayake HA, Rajapakse S, Wijesinghe PCI, Katulanda P, Jayasinghe $\mathrm{S}$

OP 054

Validity of Sri Lankan Diabetes Risk Score (SLDRISK) as a screening tool for high risk population

Rathnayake GM, Dissanayake HA, Amarasinghe PK, Katulanda P

OP 055

Anthropometric measures in screening for diabetes: should gender specific new cut-offs be used in high risk south Asian populations?

Katulanda P, Chambers JC, Katulanda GW, Dissanayake HA, Jayawardana R, Anthonis SP, Karunarathna TM, Ranasinghe G, Gamage MKW, Karunananda P, Marambe A, Weerasinghe APM, Bandara NMSU, De Silva PHLU

OP 056

Inbound health assessment in Sri Lanka: a public health good

Liyanage LSK, Chandrarathna NK, Wijesundara CR, Karunarathna JINC, Perera HSR

OP 057

Rural Health Project: the emerging challenge of obesity

Senarath U, Jayasinghe S, Katulanda P, Pathirana S, Senanayake S, Perera V, Dulanjali S, Karunaweera N, Rural Health Research Team - HETC Project
OP 058

Defensive medicine: liability for medical malpractice, protracted?

Liyanage DSEUS

OP 059

Optimization of clinical care in the state health sector by process simulation, using nonclinical data Sahabandu M, Hewapathirana R

PP 001

A study of radiation shielding characteristics of aloe vera leaf

Amarasinghe SM, Lamabadusuriya MR

PP 002

Association of T16189C polymorphism of mitochondrial DNA hypervariable region with sporadic breast cancer in women of Sri Lankan Tamil ethnicity

Kotelawala JT, Tennekoon KH, Ranasinghe R, Rodrigo HACIK, De Silva GKS, Perera WAHA, Yoganathan N, Manatunga MRS, Dissanayake DMAS, Joseph N, Rajasooriyar C, Indranath K

PP 003

The evaluation of antibacterial and antioxidant activities of endophytic fungi derived from Dipterocarpus zeylanicus

Ratnayake RD, De Silva WS, Peeris MKP

PP 004

In vitro antioxidant and antibacterial activities of endophytic fungi isolated from Mikania cordata

Ratnayake RN, De Silva WS, Peeris MKP

PP 005

Qualitative analysis of secondary metabolites and investigation of antioxidant activity of Gymnema sylvestre

Bamunuarachchi DR, Buddhapriya AN

PP 006

Development of a method to quantify the metabolites of cinnamon in human plasma

Pigera S, Ranasinghe P, Kaumal MN, Galappatthy P

PP 007

Production of cookies using sweet potato starch (Ipomoea batatas), rice flour and sunflower seed oil and determination of the scavenging activity of sweet potato cookies

Rathnayake RMVS, Gamage S, Bandara W 
PP 008

The effects of meditation on human telomere lengths in healthy individuals: A research protocol for a systematic review

Dasanayaka HMNN, Sirisena ND, Samaranayake TN

PP 009

Production of a sauce enriched with celery seeds (Apium graveolens) comprising antioxidant properties

Dharmadasa DTTLA, Bandara GMWR

PP 010

Study of Monochoria vaginalis with reference to its identification, medicinal value, distribution and conservation

Narathota SNL, Jayasiri APA

PP 011

Practices and attitude regarding self-medication with herbal home remedies for diabetes mellitus

Kumari LERN, Kumari KMHR, Lakdinithi AMAS, Witharana $\mathrm{CW}$

PP 012

Nutritional and phytochemical evaluation of an instant soup mix powder prepared by incorporation of Spirulina sp. and Gracilaria edulis

Samarakoon SMKT, Udari AHGS

PP 013

Nutritionally enhanced and value-added biscuit From Spirulina-cyanobacteria and Moringa Moringa oleifera together with natural ingredients Perera AAMD

PP 014

Comparison of the prebiotic activity of Fragaria ananassa and Vitis vinifera on Lactobacillus acidophilus

Samudika HDK, Udari AHGS, Nayomi HMD

PP 015

Development of a value-added jam product from Sonneratia caseolaris fruits and determination of the antioxidant activity

Mullegama PB, Udari AHGS

PP 016

Antibacterial properties of Tridax procumbens and Evolvulus nummularius extracts against common pathogenic bacteria

Devanjani BBH, De Silva WS
PP 017

Determination of total phenolic content and antioxidant activity of Euphorbia antiquorum $L$. stem

Dias SNCL, De Silva WS

PP 018

Analysis of large genomic rearrangements in PMS2 and MSH6 genes in a cohort of Sri Lankan patients with hereditary non-polyposis colorectal cancer (HNPCC)

Wijesiriwardhana P, Neththikumara NF, Pathirana BAPS, Sirisena UND, Wettasinghe TK, Dissanayake VHW

PP 019

Development and determination of antioxidant properties of a sauce enriched with celery seeds Dharmadasa DTTLA, Bandara GMWR

PP 020

Human mitochondrial DNA variant analysis through next generation sequencing: Identification of potential circulating biomarkers for sporadic breast cancer among Sinhalese women

Jayasekera BMLP, Tennekoon KH, Ranasinghe R, De Silva GKS

PP 021

Confirmation and characterization of a suspected deletion at the LHX4 gene locus in a child with growth hormone deficiency in Sri Lanka

Samarasinghe SASM, Hewage AS, Sundralingam T, De Silva $\mathrm{KSH}$, Tennekoon $\mathrm{KH}$

PP 022

The development of food colorant using Hibiscus rosa-sinensis and measure the quality of the colorant for a long period of storage

Kawyangana DGP, Bandara GMWR, Udari AHGS

PP 023

A novel serological tool for diagnosis of human leishmaniasis in Sri Lanka

Deepachandi MAB, Andrahennadi TP, Weerasinghe CS, Karunaweera ND, Senanayake SASC, Chatterjee M, Soysa SSSBDP, Siriwardana HVYD

PP 024

Nutritive assessment of composite flour biscuit added herbal plant powder

Dias NAIS, Bandara GMWR 
PP 025

Determination of in vitro equivalence of selected pharmaceutical products in the Sri Lankan market Thambavita D, Mannapperuma U, Nugegoda P, Galappatthy P, Jayakody RL

PP 026

A study of cytotoxicity and antioxidant activity of a Sri Lankan poly-herbal decoction and its individual components

Rupasinghe BDNU, Fernando DM, De Silva BGDNK, Soysa SSSBDP

PP 027

Antibacterial activities of some Sri Lankan medicinal plants

Madugalla SDK, De Silva WS

PP 028

Development and evaluation of the nutritional value of Ready to Serve (RTS) beverage from green milkweed climber (Wattakaka volubilis)

Reshan GHR, Udari AHGS

PP 029

Associations of genetic variations in altered cellular pathways in haematopoietic and mesenchymal stem cell compartments in Myelodysplastic Syndromes

Bandara WMMS, Rathnayake AJIS, Neththikumara NF, Goonasekera HWW, Dissanayake VHW

PP 030

Investigation of antibacterial activities of organic extracts obtained from Celosia argentea and Aporosa cardiosperma (Gaertn.) Merr.

Illangakoon IANN, De Silva WS

PP 031

Determination of blood mercury level in patients receiving Sinna Sivappu Maathirai a Siddha herbomineral drug using Atomic Absorption Spectrometry

Vijayakumar T, Balakumar S, Thileepan T, Suganthan N, Thiyahiny SN, Coonghe PAD

PP 032

Molecular cloning and expression of a selected catalytic domain of the human Cathepsin $K$ gene (CtsK) in top 10 Escherichia coli expression system Madubashetha H, Wickramasinghe S, De Silva N, Warnakula L, Cooray R

PP 033

Phytochemical analysis and antimicrobial efficacy of extracts of Dipterocarpus zeylanicus

Samad SA, De Silva WS
PP 034

Knowledge, attitudes and practices related to antibiotic use, and related factors among patients attending the outpatients department of a District General Hospital in Sri Lanka.

Rodrigo UCH, De Alwis WMHH, Jayasinghe D, Jayaweera JMS

PP 035

Selective cytotoxicity of Angiopteris evecta (Forst.) Hoffm leaves on ER positive breast cancer (MCF-7) cells

Wickramaratne NS, Thusyanthan J, Samarakoon SR, Karunaratne DN, Tennekoon KH

PP 036

Evaluation of anti-cancer activities of Mangifera zeylanica bark and leaf extracts on non-small cell lung cancer

Perera AADN, Samarakoon SR, Ediriweera MK, Tennekoon $\mathrm{KH}$

PP 037

In-vitro cytotoxicity screening of govaniadine on human cancers

Rathnayaka RMRK, Samarakoon SR, Tennekoon KH, Adhikari A, Shreshtha RLS

PP 038

Clinical and histopathological features of colorectal cancer (CRC) among Sri Lankan patients

Rahman FA, Marapana DWT, Niloofa R, Seneviratne SL, De Zoysa I

PP 039

Do diabetic female subjects tend to under-report their dietary intake compared to non-diabetic female subjects? A case control study Rathnayake RGL, Hettiaratchi UPK, Perera PPR

PP 040

Supplementation with Vitamin D3 in Vitamin D deficient adolescents - A pilot study

Kumararatne MP, Cisneros J

PP 041

The timing of hospital admission and outcome of deliveries among transferred antenatal clinic mothers from peripheral hospitals to Teaching Hospital Batticaloa, Sri Lanka

Sasikumar T, Mayuran N 
PP 042

Role of biopsy and radiological investigations in the diagnosis of paediatric solid tumours

Kumarasinghe N, Meegoda VJ, Wijayawardhana KWSM, Mahathanthila WDTA, Munasinghe TD, Bright BP, Wijekoon N, Gunaratne SA, Perera U

PP 043

Heamophagocytic lymphohistiocytosis after dengue hemorrhagic fever

Karunanayaka KASK, Bernard J, Premawansa G

PP 044

Portfolio in obstetrics and gynecology feedback for medical students at the Faculty of Medical Sciences, University of Sri Jayawardenepura, Sri Lanka Jayawardane MAMM, Pathiraja R, Silva KCDP, Fernandopulle R, Fernando A, Chandradeva VUD

PP 045

Evaluation of deficiencies in discharge summaries of surgical ward patients in Base Hospital Akkaraipattu, Sri Lanka

Sasikumar T, Mayuran N, Remance MM

PP 046

Use of FreeSurfer 6.0 for automated measurement of cortical thickness and subcortical volumes on magnetic resonance imaging data of patients with mesial temporal lobe epilepsy

Yasawardene PC, De Silva A S, Fernando MUJ, De Silva YAP

PP 047

Dosimetric comparison study of three-dimensional conformal radiotherapy against sequential intensity modulated radiotherapy in carcinoma of prostate

Dahanayake DN, Jeyasugiththan J, Kumara AW

PP 048

Parental entries regarding hearing in the Child Health and Development Record: How reliable is early detection of paediatric hearing loss?

De Alwis ASR, Yasawardene ADKSN, Rubasinghe MS, Wariyapola $\mathrm{AD}$

PP 049

A study on vitamin D status and associated symptoms among Postmenopausal women: A hospital base cross-sectional study from Northern Sri Lanka

Suganthan N, Sujanitha V, Kumanan T, Ssajibhanu K, Aravinthan M, Kesavan V, Rajeskannan_N
PP 050

The impact of pharmacist counselling on knowledge, attitudes and adherence to Clomiphene citrate in patients attending subfertility clinic at Castle Street Hospital for Women, Sri Lanka

Gajaweera WAA, Jayathilake HND, Misbahunnisa MY, Karunarathna BAOP, De Silva DTN, Batcha M, Fernandopulle BMR

PP 051

Developing and pilot - testing an oropharyngeal dysphagia screening tool for children with cerebral palsy aged $4.0-6.0$ years

Hettiarachchi S, Ravihari MGI

PP 052

Average length of stay of delivered mothers in Teaching Hospital Batticaloa, Sri Lanka

Mayuran N, Sasikumar T

PP 053

Is office hysteroscopy under simple analgesics acceptable in a local setting?

Jayawardane MAMM, Abeysekera NC, Chandradeva VUD

PP 054

Knowledge and practices regarding standard precautions and aseptic techniques among supportive staff in the National Hospital of Sri Lanka

Harshana AD, Hansini RGY, Hansini SGLS, Mathangasinghe $\mathrm{Y}$

PP 055

Management of a probable Pseudomonas pseudoalcaligenes outbreak in the Intensive Care Unit of the National Institute of Infectious Diseases, Angoda, Sri Lanka

Athukorala S, Attanayake H, Wijewickrama A

PP 056

Burden of infectious diseases in Sri Lanka

Jayasinghe PP, Iddamalgoda VL, Weerakoon KGCYSB, Wickrama WASS

PP 057

Quality of life in a patient with multiple episodes of anaphylaxis in a low resource setting

Jeewandara JMKC, Danasekara DRSR, Aberathna AMIS, Somathilake BGGK, Ranasinghe T

PP 058

Visceral leishmaniasis: an emerging health threat in Sri Lanka

Deepachandi MAB, Weerasinghe CS, Karunaweera ND, Karunanayaka P, Gooneratna L, Ratnatilaka A, Senanayake SASC, Soysa SSSBDP, Siriwardana HVYD 
PP 059

Assessment of patients' experience on hospital diet in Base Hospital, Warakapola, Sri Lanka

Mallawarachchi SMNSM, Mallawarachchi $\mathrm{CH}$, Maduragoda AP, Dalpatadu KCS

\section{PP 060}

A rare genetic split hand foot malformation: lobster claw foot syndrome

Fernando KMD, Dissanayake R, Dimal DA

\section{PP 061}

Anxiety and depression associated with dengue and other acute febrile illnesses among hospitalized patients in a medical unit in Teaching Hospital, Karapitiya, Sri Lanka

Bodinayake CK, Sevwandi RAW, Pushpakumara APARH, Wijayarathna PKPI, Jayasekara NABW

PP 062

Dimensions, correlates, management and perceptions related to pain among resident adult oncology patients

Fernando GVMC, Gunathilaka MDBD, Gayashan KDD, Dharani UGAN, Ranmali KDR, Aberathna AMIS, Jeewandara JMKC

\section{PP 063}

Exclusive enteral nutrition associated with reduced short-term surgery rates in Crohn's disease: local experiences of two inflammatory bowel disease services

Mitrev N, Lai R, Nguyen TMP, Hannah B, Leong RW, Kariyawasam V

\section{PP 064}

Availability, legibility and adequacy of diagnosis as entered in bed head ticket in Base Hospital, Balapitiya, Sri Lanka

Wanninayake WMIK, Perera HSR

\section{PP 065}

$\overline{\text { Dietary management and life style characteristics }}$ among patients with non-Insulin dependent diabetes mellitus in a primary care setting

Senevirathne PRM, Weerakoon KGCYSB, Wikrama WASS, Jayasinghe PP

\section{PP 066}

Outcome and associated factors of patients presenting to Base Hospital Wathupitiwala, Sri Lanka following road traffic accidents

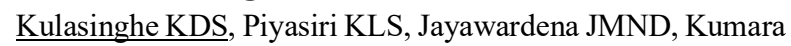
WADCR, Wickrama WASS, Jayasinghe PP
PP 067

Ethical underpinnings of mental health policy of Sri

Lanka

Gunathillaka KDK, Isuru A

PP 068

Reading fluency and reading comprehension skills of Sri Lankan Sinhala speaking children with specific learning disorders

Thennakoon TMND

PP 069

Wilms tumour in Sri Lankan children: a single center experience

Munasinghe TD, Meegoda VJ, Wijayawardhana KWSM, Mahathanthila WDTA, Kumarasinghe N, Bright BP, Perera U, Wijekoon N, Gunaratne_SA

PP 070

Higher cardiovascular disease risk in postmenopausal women compared to premenopausal women

Rathnayake KM, Hettiarachchi SS, Jackson KG, Lovegrove JA

PP 071

Susceptibility to measles among a cohort of medical students in Sri Lanka

Premathilake MIP, Gamage D, Ginige S, Gamage S, Jayalatharachchi R, Madhushanka C, Perera J

PP 072

Reproductive health problems in girls with disorders/differences in sex development (DSD): A clinic-based study

Seneviratne SN, Wickramaarachchi WAYA, Jayawardene GDCH, De Silva KSH

PP 073

Prehospital care of upper limb fractures among adolescents aged 10 to 19 years attending selected government hospitals in the Colombo district, Sri Lanka

Jayasekera SAHD, Siritunga S, Senarath U

PP 074

Quality of Life among patients with epilepsy attending the epilepsy clinic at the National Hospital of Sri Lanka

Hemanga WHB, Hemachandra HDKS, Hemini WDA, Chang $\mathrm{T}$ 
PP 075

Use of Laboratory Risk Indicator for Necrotizing Fasciitis scoring for decision making in a peripheral unit in Sri Lanka

Pathirana TH, Wijesinghe V, Dhananjaya Y, Jayasuriya HKR, Rajapaksha DC

PP 076

Study on presentation, medication adherence and glycaemic control in Diabetic Retinopathy patients presenting to the laser treatment unit of the National Eye Hospital, Colombo, Sri Lanka

Karunarathna KGDC, Karunarathne KPK, Kasthuriarachchi KACA, Abhayaratna SA

PP 077

Retinal vascular pattern variations: a preliminary study to aid developing automated diabetic retinopathy screening

Dissanayake MM, Anandanadarajah S, Ruwanpathirana PS, Dissanayake PH

PP 078

Knowledge and awareness on preeclampsia among pregnant mothers attending obstetrics clinics at De Soysa Maternity Hospital, Sri Lanka

Kandanaarachchi PK, Kahandawaarachchi SV, Karunadasa HAAS, Ranaweera GG

PP 079

Patterns and outcome of critical care admissions with circulatory shock in a medical intensive care unit of a resource limited setting

Edirisooriya M, Ranaweera AGRMA, Priyankara WDD

PP 080

Thoracic trauma patterns and outcome in National Hospital of Sri Lanka

Gamage TD, Mathangasinghe Y, Iddagoda S, Samarathunga SAPM, Bandara SM

PP 081

An audit on consultation-liaison services of the university child psychiatry unit at Lady Ridgeway Hospital for Children, Colombo, Sri Lanka

Dahanaya DMA, Samanmalee THR

PP 082

Histo-clinico-pathological description of
neuroblastomas in Sri Lanka: An institutional based retrospective study

Meegoda VJ, Wijayawardhana KWSM, Kumarasinghe N, Mahathanthila WDTA, Munasinghe TD, Bright BP, Perera U, Wijekoon N, Gunaratne SA
PP 083

The accuracy of Computed Tomography (CT) for staging colorectal carcinoma

Lokuhetty NNS, Rahman FA, Marapana DW, Niloofa R, Seneviratne SL, De Zoysa I

PP 084

Out of Intensive Care Unit intubations: Study of clinical practice and adverse events

Priyankara WDD, Samaranayake WR, Manoj EM

PP 085

Association of flavivirus infection in Transverse Myelitis

Goonetillke A, Dayarathna S, Gomes L, Druce J, Malavige N, Chang T

PP 086

Association of infection with flaviviruses with occurrence of Guillain-Barre Syndrome (GBS)

Goonetillke A, Gomes L, Dayarathna S, Malavige N, Chang $\mathrm{T}$

PP 087

Socio-demographic profile of persons with attempted suicide attending three selected hospitals in Colombo, Sri Lanka

Gurusinghe CM, Gunawardhane HPMC, Gunawardhana LDSW, Rajapakse YN

PP 088

Analysis of relationships between balance ability and walking in terms of muscle activities and lower limb kinematics and kinetics

Cinthuja P, Arnold GP, Abbound RJ, Wang W

PP 089

Implementation of a cognitive assessment protocol for patients receiving electroconvulsive therapy in a regional psychiatric hospital in Australia

Fernando WD, Luscombe G, Peris MUPK, Murugesan G, Russell A

PP 090

Factors associated with work absenteeism among health assistants in Base Hospitals, Batticaloa District, Sri Lanka

Mayuran N, SasikumarT

PP 091

Evaluation of inward patients' experiences on doctors' care in Base Hospitals, Batticaloa District, Sri Lanka

Mayuran N, Sasikumar T 
PP 092

Knowledge, attitude and usage of doping drugs among national level athletes in Sri Lanka

Nadishani KEMU, Nilaweera AI, Nipunya AG, Wijekoon NS

PP 093

A computer-aided determination of trabecular bone structural parameters of mandibular and maxillary molars for dental implants using clinical Cone Beam Computed Tomography images

Azha MAF, Dasanayake DRMS, Anuradha TMSL, Hettiarachchi PVKS, Kulatunga S

PP 094

Attitudes and knowledge of Sri Lankan speech and language therapists towards stammering

Kumara JALR, De Silva MDK, Sivasubramaniam G

PP 095

Association of quality of sleep and other factors on academic performance of the second-year students of the Faculty of Law, University of Colombo, Sri Lanka

Daniel JBM, De Mel VSD, De Mel WSB, Jayawardene DMS

PP 096

Illicit drug use and suicidal behavior: An overview of male illicit drug users in selected rehabilitation centers in Sri Lanka

Darshana ILAN, Wijesinghe CJ, De Silva PV

PP 097

Level of satisfaction, attitude towards doctors in the public sector and its associated factors, among patients attending out-patient department, National Hospital of Sri Lanka

Thilanga TJAD, Tshering P, Udara HGH, Denuwara HMBH

PP 098

Assessment on knowledge, attitudes and practices on malaria among healthcare workers, a critical element for prevention of re-establishment of malaria in Sri Lanka

Alagiyawanna AMADK, Samaranayake DBDL, Wickramasinghe DR, Premaratne RG

PP 099

An educational intervention to improve knowledge and attitude related to healthy dating relationships among undergraduates in the Western province, Sri Lanka

Fernando EHK, Jayawardana PL, Balasuriya A
PP 100

Psychological distress among school children aged 14 - 16 in a selected urban and rural schools

Yapa YMSH, Yoganandamoorthy S, Nizar MNT, Adikaram WDCN

PP 101

Efficacy of zinc as a pharmaceutical agent for the prevention of diabetes

Ranasinghe P, Jayawardena R, Galappatthy P, Katulanda P, Constantine GR

PP 102

Development of Ceylon cinnamon as a pharmaceutical agent for treatment of diabetes Ranasinghe P, Jayawardena R, Weeratunga H, Premakumara S, Constantine GR, Galappatthy P, Katulanda P

PP 103

Prevalence of overweight and gestational diabetes mellitus among pregnant mothers according to the geographical region in Sri Lanka

Kumarasinghe KHM, Kasturiaratchi K, Samarasinghe SVWS, Dimal DA, Karunarathne HMWM, Senanayaka SDPS, Jayaatilake AMA, Islam M

PP 104

Awareness, attitudes and preferences among medical undergraduates regarding counselling services at university level - with reference to University of Colombo, Sri Lanka

Balasuriya $\mathrm{CD}$, Abeysinghe BAMNW, Bandara CMSC, Abeyratne MADSN, Bandarai PKBUC

PP 105

Association of health related quality of life and grip strength with aerobic capacity among physiotherapy students, Faculty of Medicine, University of Colombo, Sri Lanka

Nadishani SKS, Kumarasinghe KHM, Jayakody JMSN

PP 106

Comparing anterior pelvic tilt \& degree of lumbar flexion with different footwear heights worn by young women in Sri Lanka

Gamage GSA, Siridewa K

PP 107

Validation of the Sinhala version of the WarwickEdinburgh Mental Well-Being Scale (WEMWBS) for use in the general population

Perera BPR, Caldera A, Wickermasinghe AR, Jaysuriya R 
PP 108

Smallpox: The direful malady that wreaked havoc in Ceylon

Careem TMZ

PP 109

Demand management in clinical laboratories in state health sector of Sri Lanka

Mallawarachchi S, Mallawarachchi $\mathrm{CH}$, Maduragoda AP

PP 110

Coping strategies and its related factors among adolescents aged 15-19 years in government schools in the Kolonnawa educational division, Sri Lanka Gamage AW

PP 111

Knowledge, attitudes and sources of information on reproductive health and sexuality in a group of adolescents in Sri Lanka

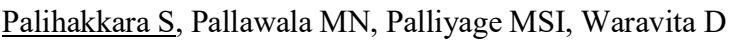

PP 112

Develop a medical protocol; my experience: Protocol for medico legal examination, reporting and management of female survivors of intimate partner violence (FSIPV) in Sri Lanka

Nanayakkara R

PP 113

Managerial aspects and quality perceptions of outsourced janitorial services of District General Hospitals of Gampaha District, Sri Lanka

Attanayake H, Wickramasinghe SC

PP 114

Establishment of a consultant-led community based oral health care delivery model in a tertiary care multispecialty public dental hospital

Gajanayake C, Perera IR, Ratnasekara NS, Nanayakkaea ANR

PP 115

Knowledge, attitudes and perceptions on mental health among advanced level students in Colombo educational zone, Sri Lanka

Gunaskera T, Wijesundara CR, Bandaranayaka K

PP 116

Effect of backpack weight and its placement on head-shoulder postural angles and peak expiratory flow rate of students in two schools in Sri Lanka Ruwanpathirana DS, Jayasena S
PP 117

Reducing the job related stress among nursing officers in Base Hospital, Horana, Sri Lanka

Wanninayake I, Nandasena S

PP 118

An intervention to improve the management and prevention of occupational sharps injuries among health care workers at base hospitals in Galle district, Sri Lanka

Ranga SDUM, Dilrukshi DARK, Dharmagunawardana D

PP 119

Improving hand hygiene compliance in the intensive care unit of the National Institute of Infectious Diseases, Angoda, Sri Lanka

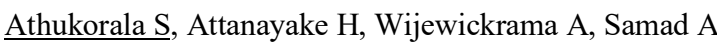

PP 120

Physical and mental well-being and job satisfaction among male construction workers in selected urban construction sites

Madushika JA, Mahathanthila WDTA, Rai M, Gunathilaka N

PP 121

Managerial experience in mitigating a probable outbreak of rabies in Base hospital, Thambuttegama Attanayake H, Ranjani A

PP 122

Relationship between smart phone usage patterns and subjective musculoskeletal symptoms in the neck and upper extremities in a cohort of Sri Lankan university students

Jayatissa PAS, Sirisena ND

PP 123

High prevalence of sarcopenia is associated with protein intake in Sri Lankan older people

Rathnayake KM, Dhanushi RGD, Jackson KG, Lovegrove JA

PP 124

Level of satisfaction and associated factors towards faculty canteens among Kelaniya medical undergraduates

Abeyrathna NMDP, Abeygunawardana PGAI, Abeysinghe AMDS, Abeysinghe AMPV, Aloka WWC

PP 125

Pre-training assessment on perceived knowledge and attitudes among lay community attending an island-wide training programme on bystander cardiopulmonary resuscitation (CPR)

Abewardana SHPEL, Nenaruwan KAN, Kerner LPVP, Kumarasinghe KHM, Wijesuriya N 
PP 126

Knowledge on non- communicable diseases and reasons for underutilization of Healthy Lifestyle Centers (HLCs) among 40-65 years old unscreened population in MOH area Galaha, Sri Lanka

Nawanelya MMSSK

PP 127

Development and internal consistency of a screening tool for assessing neurodevelopmental delay in children between 3-5 years

Caldera AV, Madhushani MR, Muttiah NA, Godamunne PKS, Chathurika LKE, Jayasena BN, Perera KMN, Tilakarathne D, Peiris MKRR, Wickremasinghe AR, Sumanasena SP

PP 128

Prevalence of musculoskeletal pain symptoms \& associated risk factors among teacher in selected secondary schools in Colombo, Sri Lanka

Ranathunge SU

PP 129

Prevalence and factors associated with unmet need for family planning among 15-49 old year women in Medical officer of Health area, Mallavi, Sri Lanka

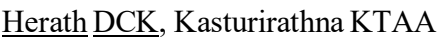

PP 130

Variability in common biochemical parameters in a selected healthy population in Sri Lanka

Panagoda DRM, Abeysuriya V, Karunaratne GHRE, Chandrasena L

PP 131

A study on prevalence of Asthenopic symptoms associated with digital screen time in bank employees of Gampaha district, Sri Lanka

Mendis DND, Munasinghe MMEM, Muzeena MMF, Naranpanawa DAP

PP 132

Knowledge, attitude and practices related to Leishmaniasis among healthcare workers in an endemic area in Southern Province, Sri Lanka

Piasiri HSB, Samaranayake TN, Priyadarshana PHMGC, Hasinthara GAS, Silva NH, Manamperi NH, Senanayake SASC, Karunaweera ND

PP 133

Need assessment for an electronic learning management system for maternal and child health staff in Sri Lanka

Karunarathne HMWM, Jayathilake AU, Kasthuriarachchi K, Senanayaka SDPS, Jayatilake AMA, Samarasinghe SVWS,
Kumarasinghe KHM, Irfaan S, Dimal DA, Islam M, Mubarak FS, Hariyaram JJ

PP 134

Acute health and comfort related issues encountered in working environment by employees in a selected government institute in Battaramulla, Sri Lanka

Munasinghe TD, Nanayakkara GATY, Mithulan P, Samaranayake TN

PP 135

Social media usage and Generalized Anxiety Disorder among grade 12 students in Colombo district, Sri Lanka

Wijesurya DC, Haroon FA, Selverajah ST, Weerakoon WMKP

PP 136

Social aspects of parents of children under 5 years of age who were admitted at the surgical casualty ward of a tertiary care hospital due to falls

Wickramaarachchi WAYA, Weerasuriya GG, Welagedara ABTMSB, Wijedasa SHDSS

\section{PP 137}

Non-Communicable Diseases (NCDs) in an indigenous rural community in Sri Lanka: A cross sectional observational study

Dalpatadu KPC, Katulanda P, Katulanda G, Samarasinghe S, Herath P, Wanninayake WMLV, Niroshan KGCI, Jayasinghe $\mathrm{S}$

PP 138

$\overline{\text { Patient satisfaction on pharmacy services provided }}$ by the outpatient pharmacy of National Hospital of Sri Lanka

Samaraweera N, Mahathevan N, Heenkenda HMAK, Dilsha RAN, Jeyanthan M, Senarathna L

PP 139

Gut colonisation of Carbapenemase producing Enterobacteriaceae (CPE) in non hospitalised individuals

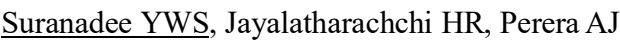

PP 140

Patterns of childhood injuries and knowledge and attitude on prevention of childhood accidental injuries among parents of children admitted with accidental injuries to Lady Ridgeway Hospital Ramamoorthy J, Jayarathna DGRRD, Jayarathna RD, Ranawaka R 
PP 141

Attitudes towards allopathic and indigenous medicinal treatment methods for musculoskeletal limb injuries from an urban public perspective

Dewasirinarayana DYB, Deshapriya RDUS, Dewapura VP, Jeevatharan $\mathrm{H}$

\section{PP 142}

Knowledge and practices on malaria surveillance among clinicians and an intervention to improve the surveillance in a hospital based setting during the prevention of re-introduction malaria phase in Sri Lanka

Ranaweera AD, Karunaratne S, Senanayake C, Jeevatharan H, Jayasooriya N, Jayasena S, Herath HDB, Fernando SD

\section{PP 143}

Portraits of illness - personal and professional development session with $2^{\text {nd }}$ year medical students, Faculty of Medical Sciences, University of Sri Jayewardenepura, Sri Lanka

$\underline{\text { Perera } \mathrm{S}}$, Wijesiriwardena I

\section{PP 144}

Readiness of the undergraduates of Faculty of Education, University of Colombo in preparing potential future medical students for technology based medical education

Ranawaka RATKG, Ranathunga YS, Sudarvannan N, Karunathilake I

\section{PP 145}

Language equality in information on
pharmaceuticals in Sri Lanka; Special reference to ongoing SCFR Case "Lionel Guruge vs NMRA and Others"

Guruge L, Dilrukshi J, Madhushan D

\section{PP 146}

Epidemiology, impact of vaccination and risk factors among laboratory confirmed Japanese Encephalitis cases reported in year 2014- 2016 in Sri Lanka

Ginige S, Gamage D, Amerasekara J, Galagoda G

\section{PP 147}

Relationship between physical activity level with social participation and risk of falls among a selected group of community-dwelling elders in Colombo district, Sri Lanka

Rajasinghe U, Dalpatadu KPC
PP 148

Narrative based learning to enhance empathy and compassion among medical students

Amarasuriya SD, Subhashini WAA, Jayasinghe S

PP 149

The attitude and influence of graphical warning signs on tobacco among males working in the Sri Lanka Railway Department

Fernandopulle JP, Gimhani WAY, Gunasekara CS, Weerakoon $\mathrm{K}$

PP 150

Study protocol: Developing a validated tool to study Buddhist meditation experience which can be used in scientific studies

Somarathne EASK, Lokupitiya E, Gunathunga MW

PP 151

Validation of a non-exercise $\mathrm{VO}_{2}$ max prediction equation among school rugby players in Sri Lanka Perera WMK, Ariyasinghe AS, Kariyawasam AP

PP 152

Students' perceptions of experiential learning: The "Assistant House Officer Program"

Samarasekara KR, Jayasinghe S

PP 153

An audit of a newly designed first page for patient record keeping

Gamakaranage C, Jayasinghe S

PP 154

Relationship between dynamic balance and gender in primary school children

Ramanayake RMCP, De Abrew WK

PP 155

Factors associated with substance abuse among drug addicts who are engaged in selected rehabilitation centres in Colombo district, Sri Lanka

Madumali AGA, Kankanamge SR, Rathnayaka RARD, Rathnayake RMSU

PP 156

The relationship between sleep quality and quality of life among shift working attendants in a tertiary care hospital in Sri Lanka

Nirodhya MMH, Nisansala NHKR, Niwashini TE, Jayasena S

PP 157

Clinical work by university academics: Should the universities continue to ignore this service?

Madurapperuma C, Gomez D, Jayasinghe S 
PP 158

Medications, physiotherapy, attitudes regarding physiotherapy and health related quality of life in patients with knee osteoarthritis attending rheumatology clinics of NHSL, Colombo, Sri Lanka Ganegoda MM, Weeraratne C

PP 159

Implementing near-peer learning: A descriptive study on resuscitation skills development module for medical students in middle income countries

Thilakasiri K, Weeratunga P, Nadarajah P, Kanchana NAS, Sigera $\mathrm{C}$

PP 160

Alteration of visual reaction time of heroin addicts with the duration of abuse: cross sectional study Sewwanda VGKM, Shaazina JFRJ, Shayila ALF, Soysa VSS, Siriwardana GK, Kumara HECS

PP 161

Social exclusion and people with mental health problems

$\underline{\text { Rathnayake A }}$

PP 162

Preliminary study of participation of mentees in the academic mentoring program, Faculty of Medicine, University of Colombo, Sri Lanka

Suranadee YWS, Premathilake MIP, Wijesinghe HD, Dilanthi HW, Witharana AWCP, Gunawardena SA, De Silva VA, Jayasinghe KSA, Gnanathasan CA, Gunathunga MW, Perera AJ, Siriwardana YD

PP 163

Knowledge, attitudes, perception and experience of doctors regarding Cardio Pulmonary Resuscitation (CPR) in a tertiary care setting

Karunarathna KWD, Karunaratne WRSA, Karunanayake KPDM, Wijesinghe HD

PP 164

Comparison of Hamstring: Quadriceps (H:Q) functional strength ratio following ligamentous knee injury in injured \& non-injured athletes from universities in Colombo District, Sri Lanka

Ruwani JMR, Wickramasinghe WWCA, Wanigasinghe J

PP 165

Balance and risk of falling in children with visual impairments

Ruwanmali PAS, Dissanayake WDN
PP 166

A workshop on Medical Humanities in Bhutan: The first in Asia

Jayasinghe S, De Abrew A, Jayasinghe D, Tenzin K, Tenzin $\mathrm{T}$

PP 167

Validation of the Self-Compassion Scale (SCS) among 14-18 year-old students in the Gampaha district of Sri Lanka

Outschoorn NO, Amarasuriya SD

PP 168

Factors associated with knowledge, attitudes and practices on sports nutrition and body composition among national level athletes in Sri Lanka

Wijerathne HMWAB, Wijerathne KMPP, Wijewardhana KWSM, Olupeliyawa A

PP 169

The impact of schoolbag carriage on musculoskeletal pain in school children from Colombo, Sri Lanka

Wickramasinghe WWCA, Pathmanathan C, Truxy HKC, Wijesiriwardana $\mathrm{W}$, Wanigasinghe $\mathrm{J}$

PP 170

Postural changes in drivers due to prolong work related sitting posture

Madushani EAPN, Dissanayake WDN

PP 171

Parental attitudes, practices and psychosocial status in preparing for the grade five scholarship examination and its association with children's performance

Kulasinghe WAYD, Kumara I, Kumarasinghe N, Jayasinghe S 